\title{
Questões do cotidiano universitário
}

\author{
Adriana Cristina Boulhoça Suehiro ${ }^{1}$
}

Joly, M. C. R. A., Santos, A. A. A. \& Sisto, F. F. (Orgs.). (2005). Questões do cotidiano universitário. São Paulo: Casa do Psicólogo.

Considerando que espaços para a discussão do cotidiano universitário são importantes para professores, alunos em processo de formação, bem como para todos os interessados nessa problemática, Maria Cristina Rodrigues Azevedo Joly, Acácia Aparecida Angeli dos Santos e Fermino Fernandes Sisto reuniram estudos que pretendem mostrar como a conexão e a adaptação à realidade atual do cotidiano universitário têm acontecido em seus mais diversos aspectos. Os doze capítulos, escritos por profissionais de Psicologia e áreas afins, referem-se a estudos relevantes para uma compreensão mais aprofundada dessa nova realidade.

No capítulo inicial, Maria Cristina Rodrigues Azevedo Joly, Acácia Aparecida Angeli dos Santos e Fermino Fernandes Sisto buscaram verificar se a grande heterogeneidade de estudantes e as mudanças relacionadas às novas exigências de adaptação ao novo ambiente acadêmico podem contribuir para a formação de barreiras à criatividade e o quanto essas barreiras podem estar relacionadas à personalidade. A falta de tempo/oportunidade $\mathrm{e}$ a inibição/timidez foram os fatores que mais atuaram enquanto barreiras à expressão da criatividade. Os estudantes ingressantes obtiveram uma pontuação média mais elevada em extroversão e, portanto, tendência a serem amistosos e ativos na interação social com seus pares.

O capítulo dois aborda a questão da compreensão em leitura e da utilização de estratégias de aprendizagem. Maria Cristina Rodrigues Azevedo Joly e Liamar Mayer de Paula verificaram, por um lado, que não houve relação entre as estratégias de aprendizagem e a compreensão em leitura, principalmente porque o nível de desempenho em compreensão dos universitários participantes classificava-os como leitores não-hábeis. Por outro lado, ressaltaram a necessidade de uma avaliação mais ampla da compreensão em leitura, considerando-se também a verificação do conhecimento prévio, do vocabulário e investigando-se sobre a dificuldade do texto para os participantes.

\footnotetext{
${ }^{1}$ Endereço para correspondência:

E-mail: dricbs@yahoo.com.br
}

Tendo em vista que o conhecimento do estilo cognitivo permite o acesso à forma de processamento cognitivo dos alunos, podendo favorecer o planejamento de currículos, o aperfeiçoamento de métodos instrucionais e de avaliação, a utilização de estratégias de aprendizagem apropriadas, entre outros, Acácia Aparecida Angeli dos Santos, Rosana Maria Mobalem Martins e Marilu de Faria avaliaram, no capítulo três, a dimensão de estilo cognitivo dependência e independência de campo, o nível de compreensão em leitura dos estudantes e as relações existentes entre os construtos. Os resultados evidenciam baixa habilidade de compreensão em leitura entre os participantes da pesquisa, a exemplo dos achados descritos no estudo realizado por Maria Cristina Rodrigues Azevedo Joly e Liamar Mayer de Paula, revelando que os alunos que possuem melhor compreensão de textos também obtiveram os maiores resultados em independência de campo.

Ana Francisca de Oliveira e Fermino Fernandes Sisto trazem sua contribuição, no capítulo quatro, apresentando estudos oriundos da literatura sobre produção de texto e inteligência fluida. Os autores buscaram verificar a relação entre a capacidade de resolução de problemas em medidas de inteligência fluida, considerando a habilidade para resolver problemas com figuras, e o desempenho escrito em redações. Não houve correlação significativa entre as medidas alcançadas na produção de texto e na Escala de Inteligência Fluida (GFRI), podendo-se pensar que a forma como o aluno resolve problemas com palavras não se correlaciona com o modo usado na resolução de problemas com figuras e que, portanto, em termos de capacidades elas são independentes.

O capítulo cinco focaliza as habilidades em escrita dos universitários ingressantes. Neide de Brito Cunba e Acácia Aparecida Angeli dos Santos detectaram, conforme apontado pela literatura, que há problemas quanto às habilidades de produção de escrita em universitários em razão da grande quantidade de erros nos 
tópicos gramaticais da escrita. Uma das explicações para essas deficiências lingüísticas é o fato de a democratização do ensino superior, e a decorrente oferta de cursos em universidades particulares, ter permitido o acesso de estudantes despreparados pelas etapas de escolarização anteriores.

Investigando barreiras à criatividade com universitários ingressantes, capítulo seis, Paula Bierrembach de Castro Guerra e Maria Cristina Rodrigues Azevedo Joly identificaram evidências de validade de construto para o Inventário de Barreiras à Criatividade Pessoal que podem ser acrescidas às já existentes em pesquisas desenvolvidas anteriormente por Alencar (1999), embora as características acadêmicas, sociais, culturais e de localização dos sujeitos estudados nos dois trabalhos sejam diferentes.

No capítulo seguinte, Fermino Fernandes Sisto, Daniel Bartholomeu, Fabián Javier Marin Rueda e José Inácio Granado buscaram, diante da escassez de estudos sobre a agressividade em universitários, verificar a existência de critérios que possam caracterizar as pessoas mais agressivas em relação ao gênero. Os resultados da pesquisa apontaram algumas condutas agressivas autopercebidas tipicamente masculinas e, outras, tipicamente femininas. Todavia, os autores concluem a pesquisa afirmando que mais do que identificar condutas mais tipicamente masculinas ou femininas e condutas comuns a ambos os gêneros talvez o cerne da questão das investigações sobre agressividade esteja no fato de que há tipos característicos de agressividade masculina e feminina.

O capítulo oito buscou verificar o nível de consistência interna do Questionário de Vivência Acadêmica (QVA), comparando os indicadores obtidos pelos estudantes universitários brasileiros e os dos portugueses. O estudo realizado por Acácia Aparecida Angeli dos Santos, Ana Paula Porto Noronha, Carina Budin Amaro e Jorge Villar evidenciou que, embora as diferenças não tenham sido significativas, houve variações entre os coeficientes obtidos entre os estudantes brasileiros e portugueses em doze das dezessete subescalas do teste, sendo os coeficientes de precisão encontrados inferiores aos verificados no estudo realizado em Portugal.

O impacto da formação universitária sobre o desenvolvimento dos estudantes e a complexidade dos processos envolvidos na evasão do ensino superior são abordados no capítulo nove. Soely Polydoro, Acácia Aparecida Angeli dos Santos, Claudette Maria Medeiros Vendramini, Elisabeth Teresa Brunini Sbardelini, Maria Nazaré Fonseca Serpa e Elisete Gomes Natário evidenciaram a impossibilidade de se isolar um indicador ou um conjunto de indicadores envolvidos na situação acadêmica de evasão em função do complexo dinamismo de interações entre fatores relacionados ao estudante, a instituição e aos eventos externos. Ao lado disso, verificaram diferentes perfis dentro do grupo de evadidos, a saber, um vinculado à experiência de reprovação e, outro, definido tomando por base a intenção de retorno ao ensino superior.

As concepções de lazer e tempo livre, bem como os fatores que incidem na realização de atividades de lazer e recreação em universitários de Educação Física constituíram-se como foco do estudo realizado por Miguel Cardozo do Lago e Fermino Fernandes Sisto. Dentre os resultados obtidos destaca-se que, em se tratando de lazer, a prática de atividade física é um dos itens mais abrangentes entre os estudantes analisados, sendo que mais da metade dos participantes considerou o lazer muito importante.

Considerando a importância da motivação dos estudantes para que a aprendizagem se concretize, José Aloyseo Bzuneck traz, no capítulo onze, um panorama dos estudos nacionais e estrangeiros sobre o tema, concluindo que, embora, a pesquisa brasileira sobre motivação no ensino superior pareça estar apenas começando, há uma vasta gama de possibilidades de trabalhos, que poderão contribuir significativamente para o ensino.

No capítulo final do livro, Evely Boruchovitch, Elis Regina da Costa e Edna Rosa Correia Neves apresentam os fundamentos teóricos da intervenção em estratégias de aprendizagem e uma breve descrição dos estudos sobre o tema nos cursos superiores. Concluem a análise desses estudos, destacando a necessidade de que a pesquisa nacional se volte para o delineamento e avaliação de programas de intervenção em estratégias de aprendizagem em áreas como leitura, escrita, solução de problemas, bem como voltados para a promoção e manutenção de estados afetivo-motivacionais adequados à aprendizagem de qualidade, sobretudo, para alunos de cursos voltados para a formação de professores.

"Questões do Cotidiano Universitário" é uma obra bastante interessante para profissionais e estudantes que, de alguma maneira, estejam envolvidos com o ensino superior e que compartilhem a necessidade de lançar um olhar mais aprofundado sobre como as mudanças intra e interpessoais se processam nesse momento que exige trilhar novos rumos e buscar por uma nova identidade. Sua organização permite que ao final da obra o leitor disponha de uma série de informações importantes sobre, por um lado, como as instituições superiores têm favorecido a aquisição de habilidades e competências ligadas às áreas específicas de atuação e, por outro, de como os estudantes têm se deparado com todo esse processo, o que faz com que o livro seja uma excelente fonte de referência.

Psico-USF, v. 11, n. 1, p. 127-129, jan./jun. 2006 
Sobre a autora:

Adriana Cristina Boulhoça Suehiro é psicóloga, doutoranda em Psicologia pelo Programa de Pós-Gradução Stricto Sensu em Psicologia da Universidade São Francisco/ Itatiba e bolsista CAPES. 
